\title{
Leukocyte Margination in Alveolar Capillaries: Interrelationship with Functional Capillary Geometry and Microhemodynamics
}

\author{
W.M. Kuebler ${ }^{a}$ G.E.H. Kuhnle ${ }^{b}$ A.E. Goetz ${ }^{b}$ \\ alnstitute for Surgical Research and ${ }^{b}$ Department of Anesthesiology, University of Munich, Germany
}

\author{
Key Words \\ Lung microcirculation - Alveolar capillaries · Functional \\ capillary geometry $\cdot$ Pulmonary microhemodynamics . \\ Leukocyte kinetics · Leukocyte margination
}

\begin{abstract}
The pulmonary capillary microvasculature harbors a large pool of intravascularly marginated leukocytes. In this study, we investigated the interrelationship of leukocyte margination with characteristics of functional capillary geometry and microhemodynamics in alveolar capillary networks. In 22 anesthetized rabbits we assessed functional capillary density, average capillary length, red blood cell velocity and leukocyte kinetics in alveolar capillary networks in vivo by intravital fluorescence microscopy. In alveolar wall areas of 12,800 $\pm 1,800 \mu \mathrm{m}^{2}$, we detected $3.6 \pm 0.5$ sticking leukocytes and $21.0 \pm 1.9$ functional capillary segments with an average capillary length of $35.7 \pm 2.1 \mu \mathrm{m}$. We calculated that approximately $15 \%$ of functional capillary segments are blocked by marginated leukocytes. Leukocyte margination was predominantly observed in capillary networks characterized by a high functional capillary density, short capillary segments and low red blood cell velocities. The multitude of interconnected capillary channels in these networks may allow alveolar blood flow to bypass marginated leukocytes. Hence, this interrelationship may be relevant for maintenance of adequate alveolar perfusion and low capillary network resistance despite excessive
\end{abstract}

\begin{tabular}{ll}
\hline KARGER & ( 1999 S. Karger AG, Basel \\
Fax +4161306 1234 & Accessible online at: \\
$\begin{array}{l}\text { E-Mail karger@karger.ch } \\
\text { www.karger.com }\end{array}$ & http://BioMedNet.com/karger
\end{tabular}

leukocyte margination in the pulmonary microvasculature. Local microhemodynamic factors may play a regulatory role in the spatial distribution of leukocyte margination.

\section{Introduction}

A large pool of neutrophil granulocytes is marginated in the dense capillary network of the pulmonary microcirculation $[1,2]$ exceeding the pool of circulating neutrophils by two- to threefold [3-5]. Neutrophil margination in alveolar capillaries has been attributed to mechanical hindrance of neutrophil transit, as a substantial percentage of capillary segments exhibit diameters distinctly smaller than mean neutrophil diameter [6]. Neutrophils thus have to deform into elongated shapes in order to squeeze through the narrow segments of the pulmonary capillary bed [7]. As neutrophil deformability is low compared to erythrocytes $[8,9]$, their transit will be delayed as compared with that of red blood cells resulting in neutrophil accumulation in the pulmonary microvasculature. In addition, leukocyte/endothelial interactions mediated by adhesion molecules of the selectin family seem to contribute to leukocyte margination in alveolar capillaries [10].

Leukocyte margination in the lung appears to be closely interrelated to functional capillary geometry and microhemodynamic characteristics in alveolar capillary networks. First, the ability of the pulmonary microvascula-

Dr. Wolfgang M. Kuebler

Institute for Surgical Research, University of Munich

Marchioninistrasse 15

D-81366 Munich (Germany)

Tel. +49 897095 4356, Fax +49 897095 8897, E-Mail wk80@columbia.edu 
ture to retain high numbers of marginated leukocytes under physiological conditions has been attributed to its unique functional capillary geometry providing an abundance of parallel and interconnecting capillary pathways: even if the entire marginated pool of neutrophils were within the pulmonary microvasculature, only $10 \%$ of alveolar capillary segments would be plugged by retained cells [11].

Second, leukocyte margination is directly counteracted by the propelling force of pulmonary blood flow, which maintains the marginated pool in a dynamic equilibrium with the pool of circulating neutrophils [12-14]. In addition, pulmonary hemodynamics can also affect functional capillary geometry by recruitment and derecruitment of single capillary segments [14].

Finally, leukocyte margination may also affect microhemodynamics and functional capillary geometry in alveolar capillary networks. Reduction of leukocyte margination has been shown to increase both functional capillary density and red blood cell velocity in alveolar capillary networks [10].

However, the complex interdependencies between functional capillary geometry, microhemodynamics and leukocyte margination in alveolar capillary networks are still unclear. A better understanding of these interrelationships may provide new insights into the characteristics and mechanisms of leukocyte margination in alveolar capillaries. Therefore, we assessed functional capillary density, average capillary length, mean red blood cell velocity and leukocyte kinetics in alveolar capillary networks of rabbit lungs in vivo and analyzed data obtained for interrelationships between these parameters.

\section{Methods}

\section{Animal Preparation}

Experiments were performed in 22 male New Zealand White rabbits $(3,017 \pm 76 \mathrm{~g}$ b.w.). All animals received care in accordance with the Guide for the Care and Use of Laboratory Animals (7th ed., 1996). The study was approved by the animal care and use committee of the local government authorities (Regierung von Oberbayern). Anesthetic regimen, preparation procedure and experimental setup have previously been described in detail $[1,10,14,15]$. In brief, anesthesia was induced by thiopental sodium (50 mg i.v.). Animals were tracheotomized and pressure-controlled ventilated (infant ventilator model IV-100, Sechrist Industries, Inc., Anaheim, Calif., USA) at an inspiratory airway pressure of $8 \mathrm{~mm} \mathrm{Hg}$, a positive end-expiratory pressure of $2 \mathrm{~mm} \mathrm{Hg}$ and an inspired $\mathrm{O}_{2}$ fraction $\left(\mathrm{F}_{\mathrm{i}} \mathrm{O}_{2}\right)$ of 0.33 . Respiratory rate was adjusted to maintain end-tidal $\mathrm{P}_{\mathrm{CO} 2}$ at $35 \mathrm{~mm}$ Hg. Anesthesia was continued by $\alpha$-chloralose $(50 \mathrm{mg} / \mathrm{kg}$ b.w. i.v.). Piritramide $(2.5 \mathrm{mg} / \mathrm{kg}$ b.w. i.v.) and pancuronium bromide $(0.3 \mathrm{mg} /$ kg b.w. i.v.) were administered for analgesia and neuromuscular blockade. Adequacy of anesthesia was controlled throughout experiments by continuous monitoring of macrohemodynamic pressures and heart rate.

Via femoral artery and vein, respectively, catheters were advanced into the aorta for measurement of arterial pressure (AP) and heart rate (HR) and into the inferior vena cava for assessment of central venous pressure (CVP) and intravenous administration of drugs and labeled blood cells. After left thoracotomy, catheters were introduced into the left atrium via the left auricle and into the pulmonary artery via the right ventricle for measurement of left atrial pressure (LAP) and pulmonary arterial pressure (PAP), respectively. An electromagnetic flow probe (Hellige, Freiburg, Germany) implanted around the pulmonary artery allowed continuous monitoring of cardiac output (CO). Transpulmonary vascular resistance (PVR) was calculated as

$$
\mathrm{PVR}=(\mathrm{PAP}-\mathrm{LAP}) / \mathrm{CO}
$$

The right fourth and fifth rib were partially resected and a transparent window was implanted into the right thoracic wall providing visual access to the surface of the right middle lung lobe.

\section{Cell Labeling and Intravital Fluorescence Microscopy}

Autologous erythrocytes were stained in vitro by fluorescein isothiocyanate (FITC) [16] and reinjected intravenously. Leukocytes were labeled in vivo by an intravenous bolus injection of rhodamine $6 \mathrm{G}(0.06 \mu \mathrm{mol} / \mathrm{kg}$ b.w.; Merck, Darmstadt, Germany) resulting in fluorescent staining of $>97 \%$ of all circulating leukocytes [14] during the entire observation period. A Ploemopak illuminator (Leica, Wetzlar, Germany) fitted with an L3 filter block for FITC and an N2 filter block for rhodamine $6 \mathrm{G}$ fluorescence (both Leitz Munich, Germany) enabled intravital fluorescence microscopy of FITC-labeled erythrocytes and rhodamine 6G-stained leukocytes in subpleural pulmonary microvessels. Kinetics of fluorescently labeled red and white blood cells in alveolar capillary networks were monitored by a silicon-intensified video camera (C2400-08, Hamamatsu Photonics, Herrsching, Germany) and recorded on videotape (video recorder AG-7350, Panasonic, Munich, Germany). Video recordings were restricted to inspiratory plateau periods prolonged to $5 \mathrm{~s}$ each in order to prevent recording of respiratory movements.

Analysis of Functional Capillary Geometry, Microhemodynamics and Leukocyte Kinetics

Microscopic investigations were performed on the lower margin of the right middle lung lobe. Only perfused capillary networks depicted clearly in the focus plane of the microscope which did not exhibit signs of edema formation, i.e. widening of interalveolar septa, were included for analysis. Video tape recordings were analyzed by the frame-to-frame technique using a digital image analysis system (Optimas, Bioscan, Edmonds, Wash., USA) with a final magnification of $\times 930$ on the video screen (WV-5470, Panasonic).

Functional capillary density, microhemodynamics and leukocyte kinetics were evaluated in capillary networks of the subpleural wall of single alveoli as previously described $[1,10,14]$. Parameters of functional capillary geometry assessed in this study refer to the functional, not to the anatomical characteristics of the alveolar capillary network. Following Krogh's definition of capillary recruitment [17] only capillaries perfused by at least a single erythrocyte during the period of observation were included, as only recruited capillaries are potential sites of leukocyte margination or red blood cell transit. 


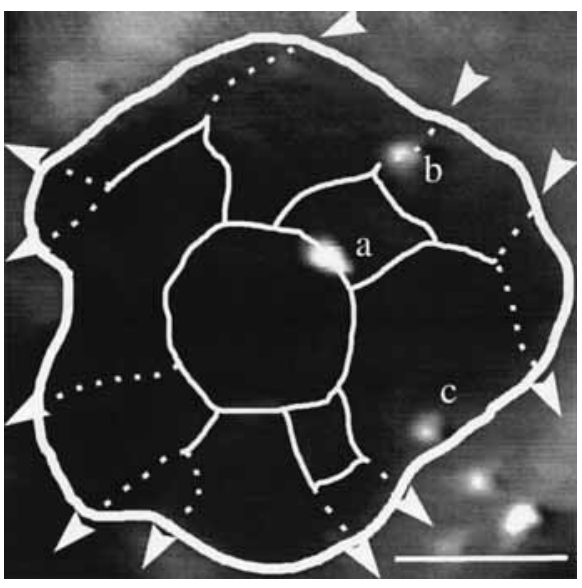

Fig. 1. Intravital fluorescence image of a subpleural alveolar wall area with rhodamine $6 \mathrm{G}$-labeled leukocytes. The boundaries of the investigated alveolar area are shown by a superimposed line sketch (solid bold line). Erythrocyte-perfused capillary pathways are visualized by superimposed thin lines. All erythrocyte-perfused segments (solid and dotted thin lines) were included for the determination of $\mathrm{CPI}$ and $\mathrm{N}_{\mathrm{SEG}}$. The depicted network consists of 28 single functional capillary segments. $\mathrm{L}_{\mathrm{Cap}}$ was assessed only from vessel segments for which both the input and the output branch point were situated within the area of observation (solid thin lines only). The in- and outflow directions of alveolar blood flow are indicated by arrowheads. Three rhodamine 6G-stained leukocytes can be seen within the capillary network of the alveolar area $(\mathrm{a}-\mathrm{c})$. Whereas a indicates a moving leukocyte, b marks a temporarily stopped and $\mathrm{c}$ a sticking leukocyte which did not move during the entire observation period. Scale bar $=$ $50 \mu \mathrm{m}$.

The alveolar wall area $\left(\mathrm{A}_{\mathrm{A}}\right)$ represents the fraction of an alveolar wall directly attached to the visceral pleura. It was measured planimetrically after tracing its boundaries defined by the surrounding interalveolar septa on the computer screen. The passage of at least 30 FITC-labeled erythrocytes and 30 leukocytes through the alveolar capillary network was analyzed. Total length $\left(\mathrm{L}_{\mathrm{A}}\right)$ of all perfused capillary segments was assessed by superimposing the pathways of all erythrocytes passing through the capillary network (fig. 1). Capillary perfusion index $(\mathrm{CPI})$ reflecting density of capillaries perfused by red blood cells within the alveolar wall was calculated according to Wagner and Latham [18]:

$$
\mathrm{CPI}=\mathrm{L}_{\mathrm{A}} / \mathrm{A}_{\mathrm{A}} \cdot 10^{4}
$$

From superimposed images of the erythrocyte-perfused capillary pathways the total number of functional capillary segments $\left(\mathrm{N}_{\mathrm{SEG}}\right)$, defined as red blood cell-perfused vessel tubes in between two bifurcations [19], within the alveolar wall area was assessed. For determination of the average capillary length $\left(\mathrm{L}_{\mathrm{Cap}}\right)$ only vessel segments for which both the input and the output branch point were situated within the area of observation were included (fig. 1). $\mathrm{L}_{\mathrm{Cap}}$ was calculated as total length of these segments divided by the number of segments.

Flux of leukocytes $\left(\dot{\mathrm{N}}_{\mathrm{WBC}}\right.$ ) through the capillaries within the alveolar wall area was calculated as number of rhodamine $6 \mathrm{G}$-stained leukocytes passing a predefined cross-section perpendicular to the major flow direction in the network per time. The velocity of each single erythrocyte $\left(\mathrm{v}_{\mathrm{RBC}}\right)$ and leukocyte $\left(\mathrm{v}_{\mathrm{WBC}}\right)$ passing the alveolar wall area was measured by tracing the cell's entire passage through the capillary network and dividing the distance traveled by the time required. Mean erythrocyte velocity $\left(\overline{\mathrm{v}}_{\mathrm{RBC}}\right)$ and mean leukocyte velocity $\left(\overline{\mathrm{v}}_{\mathrm{WBC}}\right)$ were calculated as harmonic means of single-cell velocities. Time required for passage through the capillary network of a single alveolus was assessed for each leukocyte and represents its alveolar capillary transit time $\left(\mathrm{TT}_{\mathrm{WBC}}\right)$. When passing through the alveolar capillaries, leukocytes stop frequently for distinct time periods and then continue their passage [1]. Leukocytes stopping for $\geq 0.1 \mathrm{~s}$ but moving again within the observation interval of $5 \mathrm{~s}$ were defined as temporarily stopping leukocytes $\left(\mathrm{N}_{\mathrm{TS}}\right)$ and expressed as percentage of $\dot{\mathrm{N}}_{\mathrm{WBC}}$. Time interval elapsed during each of these temporary stops $\left(\mathrm{t}_{\mathrm{TS}}\right)$ was assessed and subtracted from $\mathrm{TT}_{\mathrm{WBC}}$ of the respective leukocyte, thus enabling calculation of the flow velocity ( $\mathrm{v}_{\mathrm{WBC}}$, flow) of each individual leukocyte and the mean leukocyte flow velocity $\left(\overline{\mathrm{v}}_{\mathrm{WBC}}\right.$, flow $)$. In contrast to $\mathrm{v}_{\mathrm{WBC}}$ representing the velocity of a single leukocyte during its passage through the alveolar capillary network including temporary stops, the temporary retention of leukocytes is omitted for calculation of $\mathrm{v}_{\mathrm{WBC}}$, flow, thus representing merely the velocity of the moving leukocyte. Leukocytes that did not move during an entire observation period of $5 \mathrm{~s}$ were defined as sticking leukocytes and expressed as number of cells normalized to alveolar wall area $\left(\mathrm{N}_{\mathrm{ST}}\right)$.

\section{Experimental Protocol}

After completion of surgical preparation, we checked whether the previously defined inclusion criteria, i.e. mean arterial pressure $>70 \mathrm{~mm} \mathrm{Hg}, \mathrm{CO}>150 \mathrm{ml} / \mathrm{min}$, and lack of macroscopically visible atelectasis, hemorrhage or extensive perfusion failure on the lung surface were fulfilled.

Autologous FITC-labeled erythrocytes were reinfused and a time interval of 30 min was allowed to ensure splenic removal of rheologically altered FITC-labeled red blood cells. Rhodamine $6 \mathrm{G}$ was administered immediately prior to measurements. In each animal, erythrocyte kinetics within one alveolar wall area were video-recorded during three inspiratory plateau periods using the filter block for FITC fluorescence. Subsequently, leukocyte kinetics within the identical capillary network were recorded during six inspiratory plateau periods using the filter block for rhodamine $6 \mathrm{G}$. Following completion of video recordings, arterial blood samples were obtained for blood gas analysis (ABL 300, Radiometer, Copenhagen, Denmark) and peripheral blood cell count (T540, Coulter Electronics Inc., Krefeld, Germany). At the end of the experiments, animals were sacrificed by an intravenous injection of saturated potassium chloride solution.

\section{Statistics}

All data are given as mean \pm SEM. For correlation between single parameters, Pearson product moment correlation was calculated. Statistical significance was assumed at $\mathrm{p}<0.05$.

\section{Results}

\section{Macrohemodynamics, Blood Gases and Blood Cell Count}

Macrohemodynamic parameters, blood gases and blood cell counts determined in 22 animals under baseline conditions are given in table 1. 


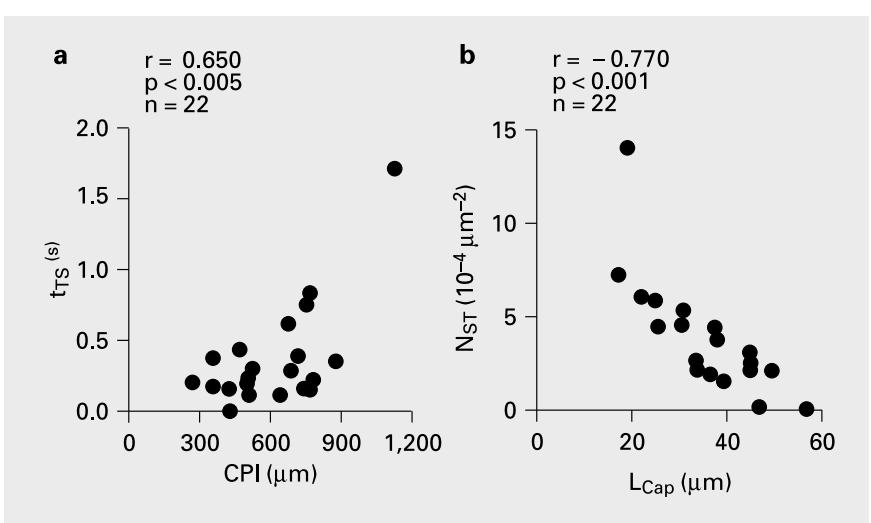

Fig. 2. Interrelationships between functional capillary geometry vs. leukocyte margination in alveolar capillary networks. Correlations between $\mathrm{t}_{\mathrm{TS}}$ vs. $\mathrm{CPI}$ (a) and $\mathrm{N}_{\mathrm{ST}}$ vs. $\mathrm{L}_{\mathrm{Cap}}(\mathbf{b}) . \mathrm{r}=$ Pearson product moment of correlation.

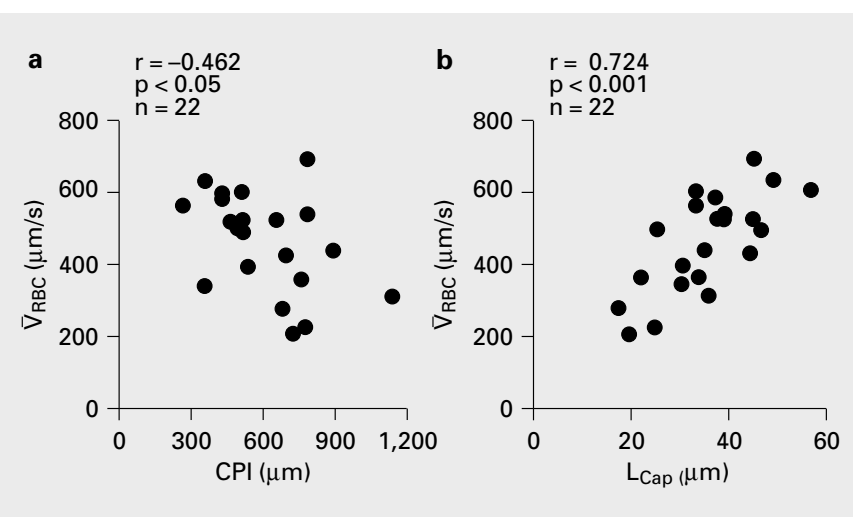

Fig. 3. Interrelationships between functional capillary geometry vs. microhemodynamics in alveolar capillary networks. Correlations between $\overline{\mathrm{v}}_{\mathrm{RBC}}$ vs. CPI (a) and $\mathrm{L}_{\mathrm{Cap}}(\mathbf{b}) . \mathrm{r}=$ Pearson product moment of correlation.

Table 1. Macrohemodynamic parameters, blood gases and blood cell count

\begin{tabular}{|c|c|c|c|c|c|}
\hline \multicolumn{2}{|c|}{ Macrohemodynamic parameters } & \multicolumn{2}{|l|}{ Blood gases } & \multicolumn{2}{|c|}{ Blood cell count } \\
\hline parameter & mean $\pm \mathrm{SEM}$ & parameter & mean $\pm \mathrm{SEM}$ & parameter & mean $\pm \mathrm{SEM}$ \\
\hline $\mathrm{AP}, \mathrm{mm} \mathrm{Hg}$ & $81.2 \pm 2.9$ & $\mathrm{P}_{\mathrm{a}} \mathrm{O}_{2}, \mathrm{~mm} \mathrm{Hg}$ & $149 \pm 10$ & Hct, $\%$ & $31.9 \pm 0.9$ \\
\hline $\mathrm{CVP}, \mathrm{mm} \mathrm{Hg}$ & $4.6 \pm 0.5$ & $\mathrm{P}_{\mathrm{a}} \mathrm{CO}_{2}, \mathrm{~mm} \mathrm{Hg}$ & $39.1 \pm 1.7$ & $\mathrm{RBC}, 10^{6} / \mu \mathrm{l}$ & $4.88 \pm 0.15$ \\
\hline PAP, mm Hg & $17.7 \pm 0.7$ & $\mathrm{pH}$ & $7.31 \pm 0.01$ & $\mathrm{WBC}, 10^{3} / \mu \mathrm{l}$ & $7.85 \pm 0.76$ \\
\hline $\mathrm{LAP}, \mathrm{mm} \mathrm{Hg}$ & $4.3 \pm 0.3$ & & & PLT, $10^{3} / \mu \mathrm{l}$ & $193 \pm 21$ \\
\hline $\mathrm{HR}$, beats/min & $249 \pm 7$ & & & & \\
\hline $\mathrm{CO}, \mathrm{ml} / \mathrm{min}$ & $193 \pm 11$ & & & & \\
\hline $\mathrm{PVR}, \mathrm{mm} \mathrm{Hg} \cdot \mathrm{min} / \mathrm{ml}$ & $0.07 \pm 0.005$ & & & & \\
\hline
\end{tabular}

Values are means $\pm \mathrm{SEM} ; \mathrm{n}=22$ animals. $\mathrm{AP}=$ Arterial pressure; $\mathrm{CVP}=$ central venous pressure; $\mathrm{PAP}=$ pulmonary arterial pressure; $\mathrm{LAP}=$ left atrial pressure; $\mathrm{HR}=$ heart rate; $\mathrm{CO}$ cardiac output; $\mathrm{PVR}=$ pulmonary vascular resistance; $\mathrm{P}_{\mathrm{a}} \mathrm{O}_{2}=$ arterial $\mathrm{O}_{2}$ tension; $\mathrm{P}_{\mathrm{a}} \mathrm{CO}_{2}=$ arterial $\mathrm{CO}_{2}$ tension; $\mathrm{Hct}=$ hematocrit; $\mathrm{RBC}=$ red blood cell count; $\mathrm{WBC}=$ white blood cell count; $\mathrm{PLT}=$ platelet count .

\section{Functional Capillary Geometry, Microhemodynamics and Leukocyte Kinetics}

Functional capillary density, $\mathrm{L}_{\mathrm{Cap}}$, microhemodynamics and leukocyte kinetics were quantified in 22 alveolar capillary networks, one per animal, with $\mathrm{A}_{\mathrm{A}}$ ranging from 3.0 to $36.1 \cdot 10^{3} \mu \mathrm{m}^{2}$ (table 2 ). In the average observed area of $12,800 \mu \mathrm{m}^{2}, 3.6 \pm 0.5$ sticking leukocytes and $21.0 \pm 1.9$ red blood cell-perfused capillary segments were detected. Under the assumption that each sticking leukocyte occludes an additional single capillary segment, $14.4 \pm 1.8 \%$ of the capillary segments were blocked by sticking leukocytes. Moreover, $46.4 \pm 4.7 \%$ of the $1.07 \pm$ 0.15 leukocytes passing the average capillary network per

Leukocyte Margination in Alveolar

Capillaries second were temporarily retained for $0.37 \pm 0.08 \mathrm{~s}$. Thus, temporary leukocyte retention occluded an additional $0.88 \%$ of functional capillary segments at a given time point.

Functional capillary density assessed as CPI correlated significantly with $\mathrm{t}_{\mathrm{TS}}$ (fig. 2a), but not with $\mathrm{N}_{\mathrm{ST}}$ (not shown). In contrast, $\mathrm{L}_{\text {Cap }}$ correlated inversely with $\mathrm{N}_{\mathrm{ST}}$ (fig. 2b), but not with $\mathrm{t}_{\mathrm{TS}}$ (not shown). These data suggest an interrelationship between leukocyte margination and functional microvascular geometry in alveolar capillary networks.

In alveolar capillary networks, $\overline{\mathrm{v}}_{\mathrm{RBC}}$ revealed a significant inverse correlation with CPI (fig. 3a) and a positive

J Vasc Res 1999;36:282-288 285 

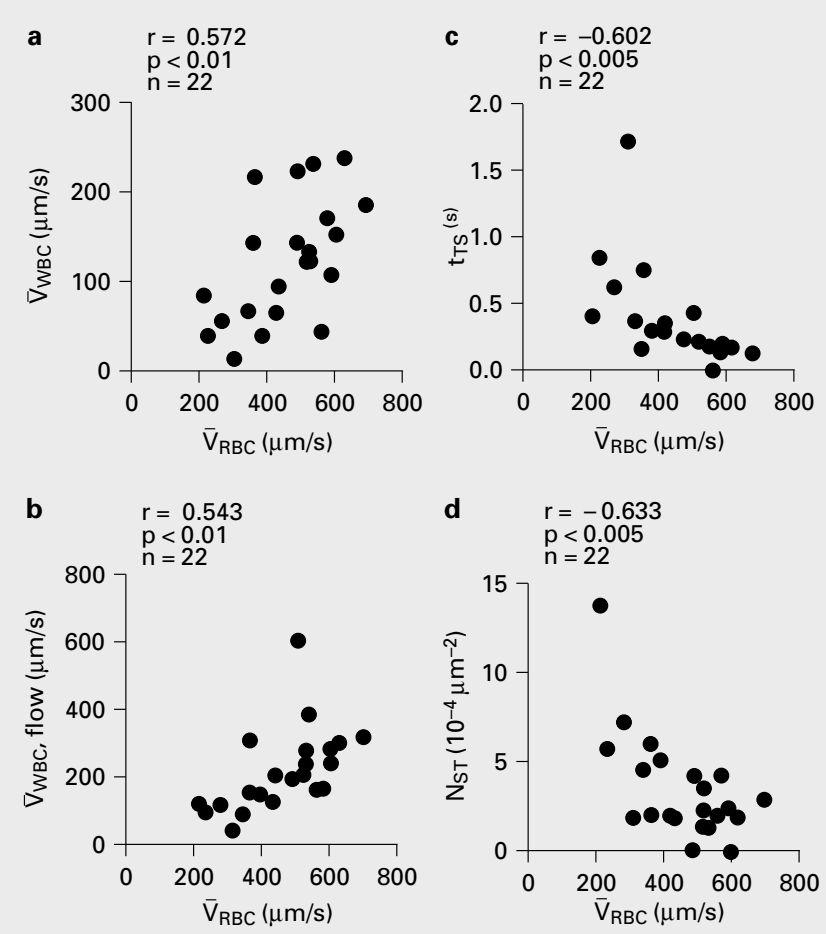

Fig. 4. Interrelationships between microhemodynamics vs. leukocyte kinetics in alveolar capillary networks. Correlations between $\overline{\mathrm{v}}_{\mathrm{WBC}}(\mathbf{a}), \overline{\mathrm{v}}_{\mathrm{WBC} \text {, flow }}(\mathbf{b}), \mathrm{t}_{\mathrm{TS}}(\mathbf{c})$ and $\mathrm{N}_{\mathrm{ST}} \mathrm{vs} . \overline{\mathrm{v}}_{\mathrm{RBC}}(\mathbf{d}) . \mathrm{r}=$ Pearson product moment of correlation. correlation with $\mathrm{L}_{\text {Cap }}$ (fig. 3 b). Hence, $\overline{\mathrm{v}}_{\mathrm{RBC}}$ was low in dense capillary networks with multiple bifurcations. Functional capillary trifurcations were not observed in any of the investigated capillary networks.

In addition, $\overline{\mathrm{v}}_{\mathrm{RBC}}$ correlated significantly with $\overline{\mathrm{v}}_{\mathrm{WBC}}$ (fig. 4a) and $\bar{v}_{\text {WBC, flow }}$ (fig. 4b) in alveolar capillaries. Finally, $\overline{\mathrm{v}}_{\mathrm{RBC}}$ correlated inversely with two parameters of leukocyte margination in alveolar capillaries, $\mathrm{t}_{\mathrm{TS}}$ (fig. 4c) and $\mathrm{N}_{\mathrm{ST}}$ (fig. $4 \mathrm{~d}$ ).

\section{Discussion}

It was the aim of the present study to investigate the interrelationships between functional capillary geometry, microhemodynamics and leukocyte margination in subpleural alveolar capillary networks of the ventilated rabbit lung. The main finding of our study is that leukocyte margination is a prominent feature in capillary networks with high functional capillary density and short average capillary length, which are characterized by low red blood cell velocities. In contrast, leukocyte margination is scarce and erythrocyte velocity high in networks with few functional capillary segments and rare branchings.

Intravital fluorescence microscopy was applied, as this is the only technique allowing for quantification of the dynamic processes of erythrocyte and leukocyte kinetics

Table 2. Functional capillary geometry, microhemodynamics and leukocyte kinetics in alveolar capillary networks

\begin{tabular}{|c|c|c|c|c|c|}
\hline \multicolumn{2}{|c|}{ Functional capillary geometry } & \multicolumn{2}{|c|}{ Microhemodynamics } & \multicolumn{2}{|c|}{ Leukocyte kinetics } \\
\hline parameter & mean $\pm \mathrm{SEM}$ & parameter & mean $\pm \mathrm{SEM}$ & parameter & mean $\pm \mathrm{SEM}$ \\
\hline $\mathrm{A}_{\mathrm{A}}, 10^{4} \mu \mathrm{m}^{2}$ & $1.28 \pm 0.18$ & $\dot{\mathrm{N}}_{\mathrm{WBC}}, \mathrm{s}^{-1}$ & $1.07 \pm 0.15$ & $\overline{\mathrm{v}}_{\mathrm{WBC}}, \mu \mathrm{m} / \mathrm{s}$ & $127 \pm 14$ \\
\hline $\mathrm{CPI}, \mu \mathrm{m}$ & $606 \pm 42$ & $\overline{\mathrm{v}}_{\mathrm{RBC}}, \mu \mathrm{m} / \mathrm{s}$ & $455 \pm 28$ & $\overline{\mathrm{v}}_{\mathrm{WBC} \text {, flow }}, \mu \mathrm{m} / \mathrm{s}$ & $225 \pm 26$ \\
\hline $\mathrm{L}_{\text {Cap }}, \mu \mathrm{m}$ & $35.7 \pm 2.1$ & & & $\mathrm{~N}_{\mathrm{TS}}, \%$ & $46.4 \pm 4.7$ \\
\hline \multirow[t]{2}{*}{$\mathrm{N}_{\mathrm{SEG}}$} & $21 \pm 1.9$ & & & $\mathrm{t}_{\mathrm{TS}}, \mathrm{s}$ & $0.37 \pm 0.08$ \\
\hline & & & & $\mathrm{N}_{\mathrm{ST}}, 10^{-4} \mu \mathrm{m}^{-2}$ & $3.5 \pm 0.62$ \\
\hline
\end{tabular}

Values are means $\pm \mathrm{SEM} ; \mathrm{n}=22$ alveolar capillary networks in 22 animals. $\mathrm{A}_{\mathrm{A}}=$ Alveolar wall area; $\mathrm{CPI}=$ capillary perfusion index; $\mathrm{L}_{\mathrm{Cap}}=$ average capillary length; $\mathrm{N}_{\mathrm{SEG}}=$ total number of functional capillary segments; $\dot{\mathrm{N}}_{\mathrm{WBC}}=$ leukocyte flux through the alveolar wall area; $\overline{\mathrm{v}}_{\mathrm{RBC}}=$ mean erythrocyte velocity; $\overline{\mathrm{v}}_{\mathrm{WBC}}=$ mean leukocyte velocity; $\overline{\mathrm{v}}_{\mathrm{WBC} \text {, flow }}=$ mean leukocyte flow velocity; $\mathrm{N}_{\mathrm{TS}}=$ percentage of temporarily stopping leukocytes; $\mathrm{t}_{\mathrm{TS}}=$ time of temporary leukocyte stops; $\mathrm{N}_{\mathrm{ST}}=$ number of sticking leukocytes normalized to alveolar wall area. 
within single microvessels in vivo. Investigations were performed in capillary networks of the subpleural pulmonary microcirculation. These networks are less densely interconnected and thus consist of longer capillary segments than those within central lung regions [20]. This is reflected by the average capillary length of $35.7 \pm 2.1 \mu \mathrm{m}$ measured in the present study, which markedly exceeds values of $8 \mu \mathrm{m}$ reported for central regions of the human lung [21]. The limitation of microscopic observations to the subpleural capillary bed has to be kept in mind for interpretation of the data presented in this study.

In subpleural alveolar capillary networks, $14.4 \%$ of functional capillary pathways were blocked by sticking leukocytes and an additional $0.9 \%$ by temporarily retained leukocytes. As single leukocytes may be temporarily retained within alveolar capillaries for periods $\geq 20$ min before continuing their passage [2], differentiation between temporarily retained and permanently sticking leukocytes may be a quantitative rather than a qualitative distinction due to the 5-second limitation of continuous microscopic observations in our model.

Assuming a total number of $277 \cdot 10^{9}$ alveolar capillary segments [21], the human lung would harbor a pool of approximately $42.4 \cdot 10^{9}$ marginated leukocytes, approximately 1.5 times the total amount of circulating white blood cells. As the marginated pool of leukocytes consists predominantly of neutrophil granulocytes, these data are in accordance with previous studies estimating the marginated neutrophil pool in the lung to exceed the number of circulating neutrophils by 2 - to 3 -fold $[3,5]$.

Leukocyte margination in alveolar capillaries markedly exceeds capillary plugging in organs of the systemic circulation, e.g. in skeletal muscle. In 440 capillary segments of rat spinotrapezius muscle investigated for $2 \mathrm{~min}$ each, Harris et al. [22] observed 111 leukocyte plugs with a mean duration of $4.99 \mathrm{~s}$, indicating that approximately $1.5 \%$ of capillary segments are occluded by leukocyte plugs at a given time point. Leukocyte margination in alveolar capillaries therefore exceeds capillary plugging in skeletal muscle by a factor of 10 .

However, this enormous intravascular accumulation of leukocytes in the pulmonary microvasculature seems to exhibit little effect on total alveolar capillary network resistance. Even in much sparser capillarized networks, e.g. a model spinotrapezius muscle network, plugging of $15 \%$ of capillary segments by marginated leukocytes increases total network resistance only by less than $20 \%$ [23]. In the dense capillary network of the alveolar microcirculation with multiple interconnecting pathways, this effect will be further minimized, as indicated by the inter-

Leukocyte Margination in Alveolar Capillaries relationships between functional capillary geometry, microhemodynamics and leukocyte margination demonstrated in this study:

Leukocyte margination was most prominent in capillary networks with a high functional capillary density and a short average capillary length. Though short capillary length is a morphological network characteristic, it points to an important role of capillary network topology in leukocyte margination, since it indicates the presence of numerous capillary branchings with an abundance in interconnecting pathways. Capillary networks with a high density of capillary pathways and multiple cross-connections were also characterized by low erythrocyte velocities. In contrast, areas with few functional capillary segments and rare intersections exhibited high erythrocyte velocities and scarce leukocyte margination.

Thus, leukocyte margination is preferentially localized in capillary areas which exhibit a multitude of patent capillary channels with multiple interconnections and therefore allow alveolar blood flow to easily bypass single capillary segments occluded by marginated leukocytes. Therefore, the effect of leukocyte margination on alveolar network resistance will be further minimized, as increased blood flow resistance by leukocytes is largely a result of impeded erythrocyte transit [24]. In addition, preferential leukocyte margination in densely capillarized alveolar networks warrants maintenance of alveolar perfusion and thus functional gas exchange capacity in each single alveolus.

As the present study merely provides correlations between parameters, the mechanisms underlying the preferential leukocyte margination in densely capillarized alveolar networks remain speculative. A possible explanation of these interrelationships is that occlusion of single capillary segments by marginated leukocytes may divert flow to other channels and recruit new capillary pathways. This would increase functional capillary density, shorten average capillary length and may also slow down erythrocyte velocity by forcing subsequent blood flow through pathways of higher resistance. On the other hand, low red blood cell velocities and thus small shear stress in functionally dense capillary networks with abundant interconnecting pathways might facilitate leukocyte margination. Accordingly, in functionally less densely capillarized areas shear stress will be high and thus leukocytes will be rapidly squeezed through the capillary segments due to hydrodynamic forces. Reduction of leukocyte margination in alveolar capillary networks by elevation of microvascular blood flow has previously been demonstrated by Kuhnle et al. [14], and inverse correlations between mean 
erythrocyte velocity and leukocyte margination could also be demonstrated in the interindividual comparison performed in the present study. However, further investigations are required to provide a more thorough understanding of the complex interrelationships between morphological and topological features, microhemodynamic characteristics and leukocyte kinetics in alveolar capillary networks.

\section{Acknowledgments}

The authors acknowledge the helpful suggestions and criticisms by Prof. Dr. med. Drs. h.c. K. Messmer and Dr. J. Bhattacharya, the supportive help by Dr. J. Groh and Dr. L. Ney, and the technical assistance of Silke Galland and Elke Schuetze. This work was supported by a grant from the Bundesministerium für Forschung und Technologie Grant 0706903A5 to A.E.G.

\section{References}

1 Kuebler WM, Kuhnle GEH, Groh J, Goetz AE: Leukocyte kinetics in pulmonary microcirculation: Intravital fluorescence microscopic study. J Appl Physiol 1994;76:65-71.

2 Lien DC, Wagner WW Jr, Capen RL, Haslett C, Hanson WL, Hofmeister SE, Henson PM, Worthen GS: Physiological neutrophil sequestration in the lung: Visual evidence for localization in capillaries. J Appl Physiol 1987;62: 1236-1243.

3 Doerschuk CM, Allard MF, Martin BA, MacKenzie A, Autor AP, Hogg JC: Marginated pool of neutrophils in rabbit lungs. J Appl Physiol 1987;63:1806-1815.

4 Athens JW, Haab OP, Raab SO, Mauer AM, Ashenbrucker H, Cartwright GE, Wintrobe MM: Leukocyte studies. IV. The total blood, circulating and marginated granulocyte pools and the granulocyte turnover rate in normal subjects. J Clin Invest 1961;40:989-995.

5 Martin BA, Wiggs BR, Lee S, Hogg JC: Regional differences in neutrophil margination in dog lungs. J Appl Physiol 1987;63:1253-1261.

6 Doerschuk CM, Beyers N, Coxson HO, Wiggs B, Hogg JC: Comparison of neutrophil and capillary diameters and their relation to neutrophil sequestration in the lung. J Appl Physiol 1993;74:3040-3045.

7 Gebb SA, Graham JA, Hanger CC, Godbey PS, Capen RL, Doerschuk CM, Wagner WW Jr: Sites of leukocyte sequestration in the pulmonary microcirculation. J Appl Physiol 1995;79: 493-497.

8 Wiggs BR, English D, Quinlan WM, Doyle NA, Hogg JC, Doerschuk CM: Contributions of capillary pathway size and neutrophil deformability to neutrophil transit through rabbit lungs. J Appl Physiol 1994;77:463-470.
9 Chien S, Sung KLP, Skalak R, Schmid-Schönbein GW: Viscoelastic properties of leukocytes in passive deformation; in Bagge U, Born GVR, Gaehtgens P (eds): White blood cells: Morphology and rheology as related to function. Den Haag, Nijhoff, 1982, pp 11-20.

10 Kuebler WM, Kuhnle GEH, Groh J, Goetz AE: Contribution of selectins to sequestration of leukocytes in pulmonary microvessels by intravital microscopy in rabbits. J Physiol 1997; 501:375-386.

11 Hogg JC: Neutrophil kinetics and lung injury. Physiol Rev 1987;67:1249-1295.

12 Martin BA, Wright JL, Thommasen H, Hogg JC: Effect of pulmonary blood flow on the exchange between the circulating and marginating pool of polymorphonuclear leukocytes in dog lungs. J Clin Invest 1982;69:12771285.

13 Lien DC, Worthen GS, Capen RL, Hanson WL, Checkley LL, Janke SJ, Henson PM, Wagner WW Jr: Neutrophil kinetics in the pulmonary microcirculation. Effects of pressure and flow in the dependent lung. Am Rev Respir Dis 1990;141:953-959.

14 Kuhnle GEH, Kuebler WM, Groh J, Goetz AE: Effect of blood flow on leukocyte-endothelium interaction in pulmonary microvessels. Am J Respir Crit Care Med 1995;152:1221-1228.

15 Kuhnle GEH, Leipfinger FH, Goetz AE: Measurement of microhemodynamics in the ventilated rabbit lung by intravital fluorescence microscopy. J Appl Physiol 1993;74:1462-1471.
16 Zimmerhackl B, Parekh N, Brinkhus H, Steinhausen M: The use of fluorescent labeled erythrocytes for intravital investigation of flow and local hematocrit in glomerular capillaries in the rat. Int J Microcirc Clin Exp 1983;2:119-129.

17 Krogh A: The number and distribution of capillaries in muscles with calculation of the oxygen pressure and heat necessary for supplying the tissue. J Physiol 1919;52:409-415.

18 Wagner WW Jr, Latham LP: Pulmonary capillary recruitment during airway hypoxia in the dog. J Appl Physiol 1975;39:900-905.

19 Okada O, Presson RG Jr, Kirk KR, Godbey PS, Capen RL, Wagner WW Jr: Capillary perfusion patterns in single alveolar walls. J Appl Physiol 1992;72:1838-1844.

20 Guntheroth WG, Luchtel DL, Kawabori I: Pulmonary microcirculation: Tubules rather than sheet and post. J Appl Physiol 1982;53:510515.

21 Weibel ER: Morphometry of the Human Lung. New York, Academic Press, 1963.

22 Harris AG, Skalak TC: Leukocyte cytoskeletal structure determines capillary plugging and network resistance. Am J Physiol 1993;265: H1670-H1675.

23 Warnke KC, Skalak TC: The effects of leukocytes on blood flow in a model skeletal muscle capillary network. Microvasc Res 1990;40: 118-136.

24 Helmke BP, Bremner SN, Zweifach BW, Skalak R, Schmid-Schönbein GW: Mechanisms for increased blood flow resistance due to leukocytes. Am J Physiol 1997;273:H2884H2890. 